\title{
Effect of Deltamethrin on the Testicular Tissue of Albino Rats
}

\author{
Zainab Ismail Ibrahim \\ Veterinary Medicine College, Department of Pathology and Poultry Diseases University of Baghdad, Bagdad \\ E-mail: Zainabaalrubaei@covm.uobaghdad.edu.iq
}

\begin{abstract}
This experiment aimed to investigate effect of changes of deltamerthrin on the testicular tissues of adult males' rat. Twenty-four adult male rats after their acclimatization for three weeks divided randomly and equally into three groups ( $n=8$ rats): The LD50 of deltamerthrin was $150 \mathrm{mg} \mathrm{kg}^{-1}$. The experimental rats were inoculated orally with deltamerthrin 1/10 and 1/20 LD50 daily for 60 days. At the end of experiment animals were sacrificed post euthenization. For post mortem examination the testes were preserved in $10 \%$ formalin then processed with graduated concentrations of ethyl alcohol for impregnation in liquid paraffin then sectioned about 4-6 $\mu \mathrm{m}$ stained with hematoxylin and eosin staining for microscopic examination. Deltamethrin with have significant Histopathological effects on male'stestes of rats. Hyper chromatic germ cells with rounded cells inside the lumen of seminiferous tubules with apoptotic cells, decreased mature sperms inside the lumen (hypospermatogensis), severe necrosis, damage of spermatogonial layers, atrophy and shrinkage of seminiferous tubules, reflected marked reduction of spermatozoa and decreased Leydig cells.
\end{abstract}

Keywords: Deltamethrin, Histopathology, Tests of rats

Deltamethrin is among the most popular and widely used insecticides in the world but is toxic to aquatic life, particularly fish, and therefore must be used with extreme caution around water. Although generally considered safe to use against humans but still show neurotoxicity to humans. Deltamethrin is able to pass from a woman's skin through blood and into her breast milk (Bouwman et al 2006). It is an allergen and causes asthma in some people (Erdogan et al 2006). Deltamethrin prevent the spread of diseases carried by tick-infested prairie dogs, rodents and other burrowing animals. It is helpful in eliminating and preventing a wide variety of household pests, especially spiders, fleas, ticks, carpenter ants, carpenter bees, cockroaches and bed bugs. In rat deltamerthrin was poorly absorbed through the skinand left the body within 24 hours (Bradberry et al 2006). The objective of study is to evaluate the Histopathological changes occurred in testes post oral administration of deltamerthrin in rat.

\section{MATERIAL AND METHODS}

Twenty-four male albino rats aged about three months and body weight ranged between $150-200 \mathrm{gm}$ were raised and bred in the animal house of College of Veterinary Medicine, University of Baghdad. The animals were kept in cages of $\left(20^{*} 30^{*} 50\right) \mathrm{cm}^{3}$ dimensions withaverage of three rats in each cage one month before study for acclimatization in optimum conditions of breeding at $22 \pm 3{ }^{\circ} \mathrm{C}$ with a 14/10hours light/dark cycle .Commercial feed pellets and drinking water were given all the time of experiment
(O'Malley 1997). LD50 was calculated as $150 \mathrm{mg} \mathrm{kg}^{-1}$. The treatment included 1/10 LD50 and 1/20 LD50 dose of deltamerthrin was administered orally daily to three groups of rats along with control. The experimental animals were sacrificed after 60 days for pathology study including the gross and histopathology examination of the testis. The piece of testis were dissected free of connective tissues, then submitted to preservation in formalin $10 \%$. Histopathological processing and staining with hematoxyline and eosin stain were performed according to Peterson et al (2011).

\section{RESULTSAND DISCUSSION}

Clinical observations: Most of significant clinical signs were obvious on rats treated $1 / 10$ LD50 rats were neurobehavioral signs, emaciation and weakness which reflect the direct effect of toxin and damage the defense barriers of internal organs, like cross toxin blood-brain barriers and injured the endothelium lined blood vessels of meninges to cause severe neurodegenerative changes mainly 60days from experiment

Histopathological changes of the testes: The microscopic changes of the testes treated with deltamerthrin were summarized as degeneration and depletion of elongating spermatid, hyper chromatic germinal layer of spermatogonia, abnormal space between neighboring sertoli cells, also there was complete loss of spermatocytes lining-epithelium that sloughed into the lumen with rounded cells inside the lumen of seminiferous tubules left only base spermatic cells in the lumen of seminiferous tubule, 
thickening of the testicular capsule due to congestion of blood vessels sinuses and edema in the interstitial between tubules. Hyper chromic germ cells and some apoptotic figures showed with rounded cells inside the lumen of seminiferous tubule (Fig. 1). The Figure 2 showed hyper chromic germ cells with different degree of necrosis of spermatocytes accumulation of rounded cells in the lumen, the different degree of necrosis and some with severe destruction of germ cells and no spermatocytes found inside the lumen of the seminiferous tubules (Fig. 3). The different degrees of necrosis of germ cells and accumulation of the rounded cells inside the lumen of the seminiferous tubules with thickening of the testis wall due to congested blood vessels (Fig. 5). Finally increase in the rounded cells in the section (necrosis) with hypo spermatogenesis and leading cells decreased (Fig. 5). The study indicate that deltamerthrin caused damage of the defense barriers of

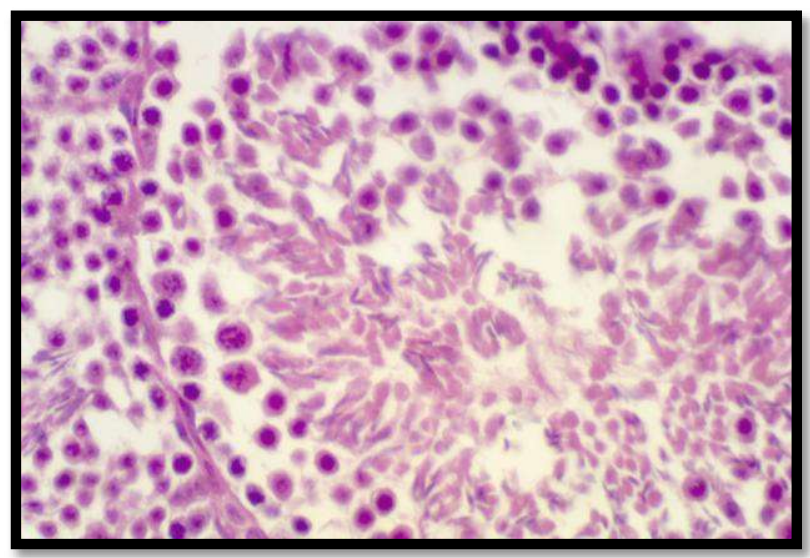

Fig. 1. Histopathological section of the testes shows; hyper chromic germ cells and some apoptotic figures showed with rounded cells inside the lumen of seminiferous tubules, (H\&E stain, 400X)

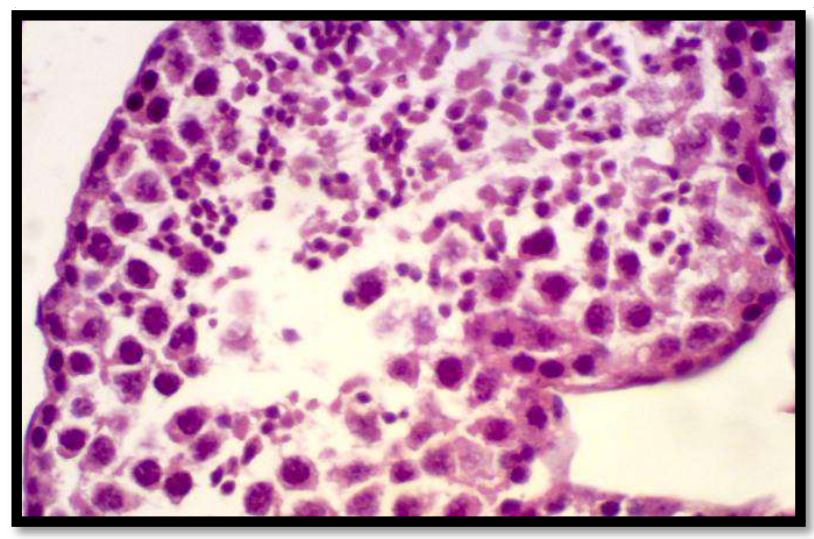

Fig. 2. Histopathological section of the testis shows; hyper chromic germ cells with different degree of necrosis of spermatocytes (accumulation of rounded cells in the lumen) (H\&E stain, 400X).

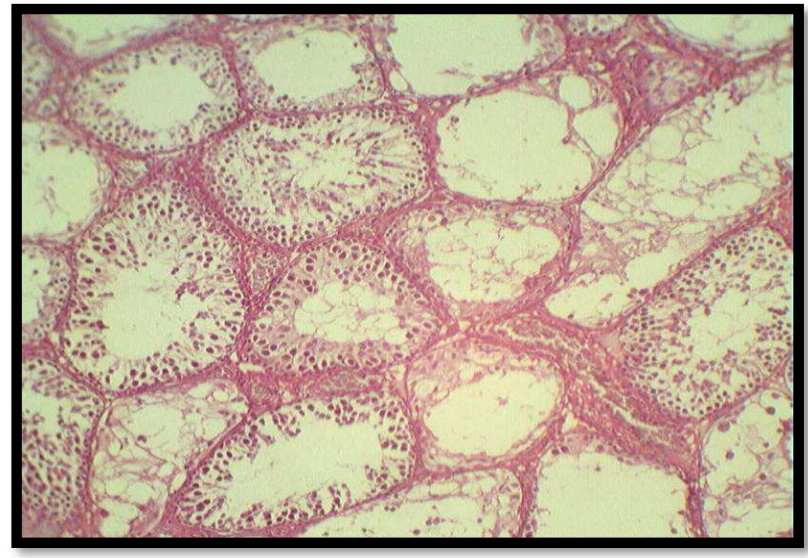

Fig. 3. Histopathological section of the testes shows: different degree of necrosis and some with severe destruction of germ cells and no spermatocytes found inside the lumen of the seminiferous tubules (H\&E stain, 400X)

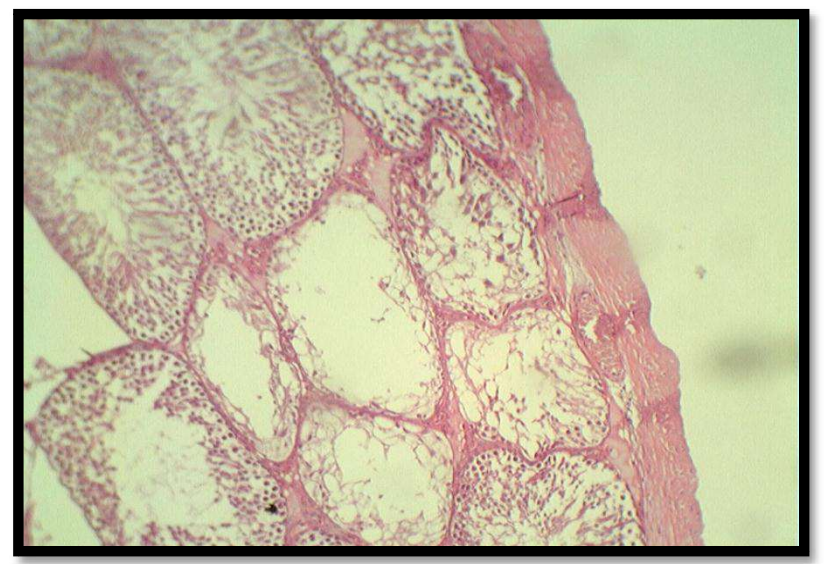

Fig. 4. Histopathological section of the testes shows: different degree of necrosis of germ cells and accumulation of the rounded cells inside the lumen of the seminiferous tubules with thickening of the testis wall due to congested blood vessels (H\&E stain, 100X)

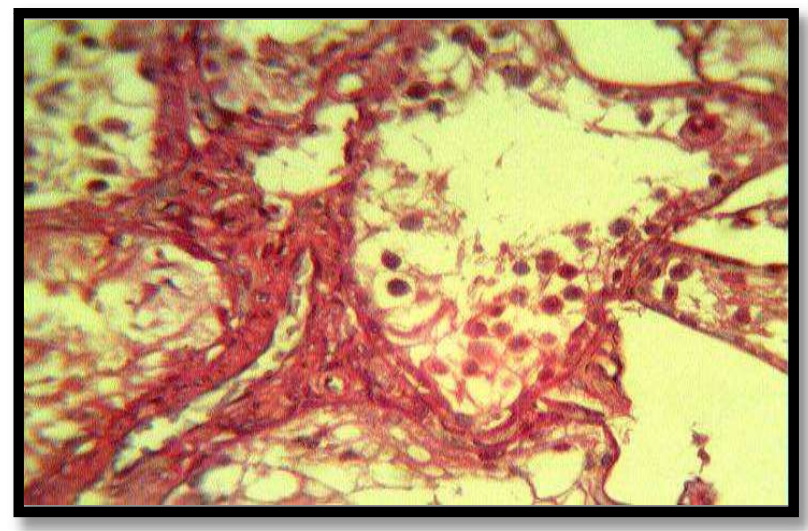

Fig. 5. Histopathological section of the testes showed: increase the rounded cells in the section (necrosis) with hypo-spermatogenesis, leydig cells decreased (H\&E stain, 400X) 
internal organs, like cross toxin blood-brain barriers and injured the endothelium lined blood vessels of meninges to caused severe neurodegenerative changes mainly at 4 and 6 weeks and also lead to congestion of the internal organs and also linked to the production of reactive oxygen species (ROS)resulting in oxidative stress in animals which could cause a damage to the mitochondria of the cells and then lead to death.

\section{CONCLUSIONS}

The oral administration of deltamerthrin15 $\mathrm{mg} \mathrm{kg}^{-1}$ demonstrated the destruction of the spermatocytes with mild degeneration of seminiferous tubules and mild decrease of leydig cells with appearance of the rounded cells inside the lumen of it with decrease the mature sperms.

\section{REFERENCES}

Bouwman B, Sereda HM and Meinhardt HB 2006. Simultaneous presence of DDT and Pyrethroid residues in human breast milk from a malaria endemic area in South Africa. Environmental
Pollution 144(3): 902-917.

Bradberry SM, Cage SA, Proudfoot AT and Vale JA 2006. Poisoning due to pyrethroids. Toxicology Review 24(2): 93-106.

Erdogan S, Zeren EH, Emre M, Aydin O and Gumurdulu D 2006. Pulmonary effects of deltamerthrin inhalation: an experimental study in rats. Ecotoxicology and Environmental Safety 63(2): 318-323.

Manna S, Bhattacharyya D, Mandal TK and Das S 2005. Repeated dose toxicity of deltamethrin in rats. Indian Journal of Pharmacology 37(3): 160-164.

Metcalf JA,Gallin JI, Nauseef WM and Root RK 1986. Laboratory Manual of Neutrophils Function. 1986, Revan Press: New York: 768.

Nitin D, Khan AM and Raina R 2013. Sub-acute deltamethrin and fluoride toxicity induced hepatic oxidative stress and biochemical alterations in rats. Bulletin of Environmental Contamination and Toxicology 91(3): 334-338.

O'Malley M 1997. Clinicalevaluation of pesticide exposure and poisonings. Lancet 349: 1161-1166.

Peterson TS, Spitsbergen JM, Feist SW and Kent ML 2011. Luna stain, an improved selective stain for detection of microsporidian spores in histologic sections. Diseases of Aquatic Organisms 95(2): 175-180.

Tomlin CDS 2009. The pesticide manual: A world compendium, No. Ed. 15. British Crop Production Council, PP.45 